\title{
2 From the Mainstreaming of Western Science to the Co-Evolution of Different Sciences Addressing Cognitive Injustice
}

\author{
Bertus Haverkort \\ Retired agricultural development specialist and author
}

\section{CONTENTS}

Introduction: Cultures, Worldviews and Sciences .................................................................... 21

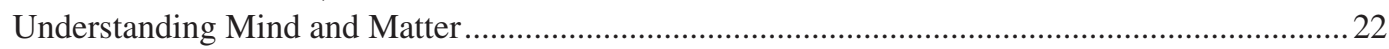

Agricultural Practices from Different Worldviews .............................................................. 23

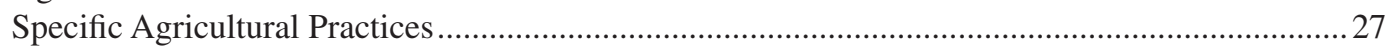

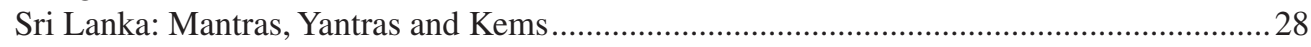

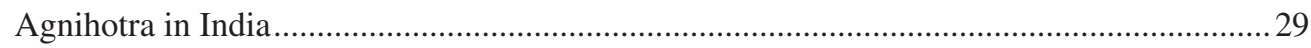

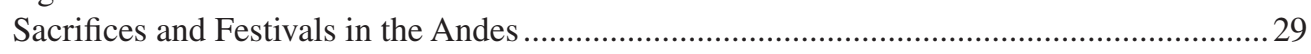

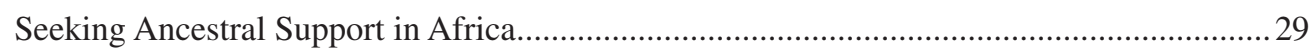

Harmonising the Earth and Cosmic Forces in Europe.......................................................29

The Trans-Cultural Notion of Science and Its Co-Evolution....................................................... 31

Scenarios for Inter-Science Relations: From Domination to Complementarity ........................... 33

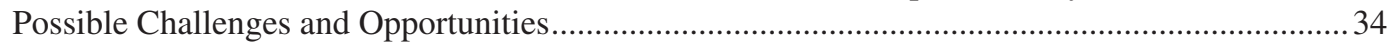

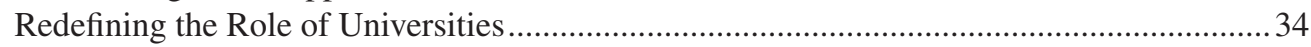

Dealing with the Strong and Weak Points within the Dominant Forms of Knowledge .......... 36

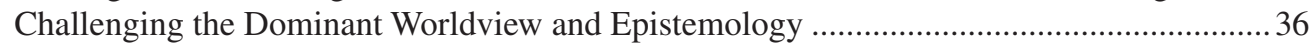

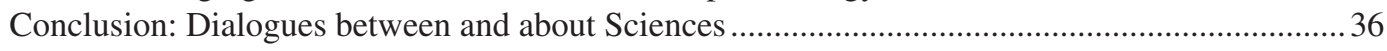

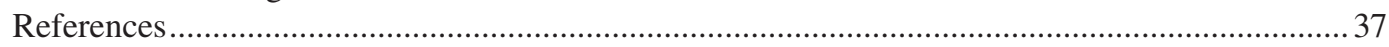

\section{INTRODUCTION: CULTURES, WORLDVIEWS AND SCIENCES}

Presently, the mainstream, Western-based (or modern) sciences are taught, developed and applied in all corners of the globe and have a very strong position because of the attribution of their effectiveness, reliability, applicability and their funding and recognition by the main private and public actors. Yet, till today there is still a great diversity of ways in which different people in different cultures acquire and process knowledge and formulate their own sciences. How people actually know and handle knowledge depends on the worldviews of particular knowledge communities, and the methods they use for learning, their logic and values. Even though mainstream sciences often displace local (or native or indigenous) sciences, a considerable number of local sciences are still being applied, and reproduce themselves despite their marginal position. Over the last two decades, there are a number of initiatives that aim at 
revitalising local knowledge systems - and local sciences - and these search for complementarity and synergy between different sciences.

These initiatives assert not only that global diversity has a physical and biological component, but also that cultural and scientific diversity is also important. In different parts of the globe, indigenous and local experts publish about the scientific basis of their knowledge systems: in New Zealand (Bishop, 1998; Tuhiwai Smith, 1999), Canada (Battiste, 2005), the USA (Barnhardt and Kawagley, 2005; Cajete, 2000; Mihesuah and Wilson, 2004), South America (Rist and Delgado, 2009), Africa (Millar et al., 2006) and India (Balasubramanian and Nirmala Devi, 2006). A great number of research and educational programmes are emerging that aim at revitalising local knowledge traditions, and these seek a complementary relationship with other sciences. These range from the United Nations University Institute of Advanced Studies - Indigenous Knowledge Initiative, and the Inter-institutional Centre for Indigenous Knowledge located in the College of Education at Pennsylvania State University, which comprises more than 20 indigenous knowledge resources centres in North and South America, Europe, Asia, Africa and Oceania, to the Indigenous Women's Network that was founded in 1985 and has a journal of the same name. These indigenous scholars, researchers and institutions address questions such as the following:

- What are the worldviews, basic principles, values and methods according to which learning takes place in different cultural environments?

- What are the strengths and weaknesses of different sciences and what can be done to increase the effectiveness and innovative character of these ways of learning?

- How can the marginalisation and suppression of local sciences be addressed? And

- How can complementarity and co-evolution of sciences be achieved?

Proponents of this approach take the position that neither experiences and methods from minority cultures nor those of the mainstream approach are inherently the most appropriate to explain reality and/or to develop technologies that improve quality of life. The latter may be used to complement local learning processes, but they should not replace them, as is often the case. Exchange between different sciences, and co-evolution rather than domination and substitution are seen as important.

\section{UNDERSTANDING MIND AND MATTER}

Amongst the different worldviews and sciences that exist today, reality is considered and understood in different ways. Globally, a divide can be observed between those who believe that reality is made up of only one basic substance (monists) and those who believe that reality is made up of two different substances (dualists).

Monists focus either on matter or on mind. Materialism asserts that mind is basically a result of biochemical processes. This position is dominant in modern Western paradigms. Within monism, positions that consider reality to be based on spiritual or mental principles are labelled as idealism. These positions are often held in non-Western cultures, and specifically so in the Vedic tradition. Modern science has been struggling with the relation between monism and dualism. It mostly accepted that both realities exist (dualism), but in their research practice, modern scientists address only the quantifiable, which is the material reality.

During the Enlightenment period, the foundations of scientific reasoning were laid by various traditions, including Empiricism by Francis Bacon (1561-1626), Rationalism by Descartes (1596-1650) and Mechanism by Newton (1642-1727). The development of Evolutionism by Darwin (1809-1882) and Classical Economics by Adam Smith (1723-1790) emerged from this scientific revolution with major implications for the worldviews and the way social systems were considered and organised.

Rene Descartes believed in the possibility to reach absolute truth through scientific knowledge. His approach was based on the belief that all aspects of a complex phenomenon can be 
understood by reducing them to their constituent parts, a process called atomisation. He made a clear distinction between mind and matter and replaced the notion of the divine plan of the Creator with a mathematical order of nature. Descartes understood humanity as composed of two independent substances: body and mind. But, he thought that it was only the ratio and quantification of objective phenomena that could lead to good knowledge. During the Enlightenment, the dominant worldview became materialistic: in order to make reality researchable, it became necessary to separate mind from matter, humankind from nature and subject from object. The only thing that could objectively be observed and experienced was matter, and so mind became considered as terra incognita by scientists, a tradition that continues to this day. This Cartesian science has a linear view of time, a mechanistic notion of cause and effect. It values quantity more than quality and is organised into highly specialised and atomised disciplines. The theory of evolution, based on the notion of 'survival of the fittest', has been translated over to economics as the mechanism of competition between commercial entities where the 'winner takes all'. Human traits such as altruism, friendship, cooperation, love and affection have been attributed less importance than competition, individuality, aggression and conquest. This has led to a justification of political and economic domination and acceptance of cultural and biological extinction as part of the price for progress.

Since the colonial period, this version of Western-based science, in combination with Western religions, was disseminated in the South and, to a certain extent, it substituted the various - often animistic - indigenous knowledges, sciences and belief systems. The latter were declared inferior, backward and superstitious and were regarded as a bottleneck to modernisation and development, as were the pre-Enlightenment belief systems in the North.

Western science has led to impressive technologies and highly productive systems of agriculture and industry, impressive medical achievements and communication systems. But it has not fulfilled its promises to serve human needs and allow progress for all. The widespread application of modern technologies has definitely improved food production, health systems and labour conditions in parts of the globe, but not the entire globe. Where it has worked well has often been at the expense of some categories of people. In southern countries, the overlapping categories of women, rural people and peasant farmers have suffered most. ${ }^{1}$ Advancements in modern technology have not led to global peace, ecological stability and social or psychological well-being. Nor have they led to the eradication of widespread hunger or poverty, not even in northern countries, where in spite of affluence, pockets of poverty exist amongst certain communities, and where food systems also cause a serious problem through affluence: obesity and environmental and climatic impacts. This situation justifies a search for new worldviews and scientific methods that challenge Western knowledge's claim to exclusive universality, and a great number of organisations and movements are engaged in this effort. An illustration of the diversity of worldviews and ways of learning is presented in Box 2.1, with some insights from India, Ghana and Bolivia.

\section{AGRICULTURAL PRACTICES FROM DIFFERENT WORLDVIEWS}

From the year 2000 to 2012, two different international programmes have carried out action research to strengthen indigenous knowledge and practices and to enhance endogenous development (development from within). These programmes covered 16 different countries worldwide: Bolivia, Mexico, Guatemala, Chile and Colombia, Ghana, Kenya, Zimbabwe, Uganda and South Africa, Norway, the Netherlands, India, Sri Lanka, Nepal and Indonesia. The first programme was COMPAS, a programme in which several NGOs and a number of universities carried out fieldwork.

\footnotetext{
${ }^{1}$ For a comprehensive overview and critical analysis of the role of peasantry in Peru, Italy and the Netherlands, see van der Ploeg (2008).
} 


\section{BOX 2.1 DIFFERENT WORLDVIEWS, WAYS OF LEARNING AND WAYS OF KNOWING}

India: In the Vedic tradition, the real world and the fundamental principles upon which life systems are organised are different from those in the West (Balasubramanian and Devi, 2006). Reality is a continuum of matter, mind and consciousness. Vedic knowledge has a notion of 9 existential principles, 41 qualities and 5 types of action, upon which, for example, the Ayurvedic health system is based. The term Akasha refers to the unifying energy inherent in all four elements (earth, air, water and fire) in nature and thus also in every living creature. Essentially, it is the all-encompassing spirit energy. In this worldview, all entities can learn, and learning is not limited to the use of the five senses. It takes place through a combination of sensory perception, intuition, inference and teachings of seers or gurus. If the mind is free from prejudices (lust, anger, greed, intoxication, delusion and jealousy), it can learn from within. Meditative techniques and yoga are used in addition to ancient written texts in the pursuit of knowledge for liberation and Enlightenment. Lessons from previous lives can also play a role. In India, traditional knowledge and practices coexist parallel with mainstream knowledge. Ayurvedic hospitals coexist with hospitals based on Western medicine.

Latin America: The Andes: Studies by AGRUCO (AGRUCO 2001; COMPAS-AGRUCO 1998) revealed that in the Andean worldview, the natural, social and spiritual worlds are united. Sacred time-space (Pacha Mama) goes beyond the physical or socio-economic domains. There is a spiral notion of time that is not separated from space (territory); the first ordering principle is relation; everything is related and this leads to a reciprocal relationship between humans, animals, plants, rocks, water, wind, sun, moon and stars. These relations are embodied in astronomy, rituals and fiestas. In these cultures, learning takes place by experiencing the relationship between the human, the natural and the spiritual worlds. 'It is through our connection with Pacha Mama that we learn' (Millar et al., 2006). Learning from within is based on intuition and lessons from nature. More than being interested in mechanical explanations of 'how things are', there is an emphasis on the question 'why things are'. In asking 'why', the interaction between the human, the material and the spiritual world is taken as a given; questions of moral and ethics play an important role, as human behaviour can have a direct influence on the natural and spiritual worlds. In the Andes, traditional and mainstream knowledge have a so-called syncretic relationship. Some traditional concepts have been redefined by mainstream to fit their frame of reference, but continue to be used in the traditional communities. The notion of Pacha Mama has been replaced by Gaia, sometime in combination with the Virgin Mary.

Africa: In the worldview of the Dagaba people in Northern Ghana, the world is made up of ancestors, the living and the not-yet-born, and nature is sacred (Millar et al., 2006). Within this worldview, there is a hierarchy between divine beings, spiritual beings, ancestors, living human beings and natural forces. Nature provides habitats for human and spiritual entities. Time is cyclic and goes from the present to the past. Ancestral spirits have powers that can be used in both negative and positive terms. In the present-day African reality, one can observe two coexisting systems of beliefs and knowledge: traditional and modern. The modern system is formally accepted, but the traditional system persists often in an underground way. The traditional systems are labelled as satanic by imported religions and as superstitious by mainstream scientists. Both traditional and mainstream sciences are based on specific values, logic and interpretation of cause-effect; this often leads to different choices about lifestyle, spirituality and practices of farming and health. In addition, the ways of learning are different. In the traditional African view, learning implies being receptive 
to the teachings of those who have lived before us, the elders, and reading the signals of the spiritual world expressed in nature. Also here, the emphasis of learning is more on 'why things are than on how things are'.

The West: In the 'Enlightenment' view, knowing is based on measuring and the use of the five senses. Rational logic, materialism, mechanism and self-interest of the individual or group are strong ordering principles through which Western people comprehend reality. There is also a perceived duality, expressed in dichotomies such as mind-matter, creator-created, man-nature and object-subject. Science is organised and developed in separate disciplines. In this materialist and mechanistic view, learning is done by subjects that are separate from objects, and quantifiability is important. The emphasis of research and of learning is on 'how things are': how a certain effect is caused within the laws of physics or other sciences. In the 'Postmodern' view, the world is regarded more from a holistic perspective, where uncertainty, diversity, chaos and self-regulation, and synergy are seen as ordering principles. It takes distance from or relativises generic principles and universal science. Sources of knowing include Pre-Enlightenment views, new scientific insights from quantum mechanics and transdisciplinarity, systems thinking, chaos theory, social learning and a diversity of ways of knowing and ways of learning from non-Western cultures.

It set up cooperation between indigenous organisations and development organisations. The most important point was to understand and articulate the worldviews and values of the indigenous people and then to design and test practical ways to strengthen local knowledge. The second programme, CAPTURED, aimed to develop educational material and research methods for universities in their role of enhancing endogenous development.

The results of these programmes (COMPAS, 2007; Haverkort et al., 2003; Haverkort and Reijntjes, 2006) revealed the following:

- In all countries, major changes in political autonomy, demography, economic and cultural integration, technological innovations, exposure to mass media and degradation of environmental resources have taken place and are leading to an erosion of indigenous cultures, knowledge and cosmovisions.

- At the same time, despite the South's apparent acceptance of the dominant technologies, beliefs and values, below the surface a persistent core of indigenous culture survives and a wealth of indigenous knowledge on natural resource use still exists. This determines the values and decision-making of rural populations.

- Many cosmovisions of indigenous farming communities are based on a holistic concept: the reality in which farming takes place generally encompasses the natural world, the human world and the spiritual world (see Figure 2.1). Mankind, the spiritual world and nature are often seen as having a reciprocal relationship. If nature is not treated well, it may react by treating the people badly, through, for example, a plague, a drought or a bad harvest. If the spirits are respected, they will ensure a good life for living creatures. People, therefore, look upon farming not only as an activity in the natural world, but also as an activity in the spiritual world.

- Peoples' understanding and description of the spiritual world is frequently rich, diverse and structured. It is experiential and can be based on the teachings of persons with visions, such as spirit mediums or shamans. It can be expressed in classical texts such as the Vedas, or in linguistic or artistic symbols. The spiritual world is seen as containing both a creative force and a destructive force. There may be a polarity of good and bad forces, and there are 

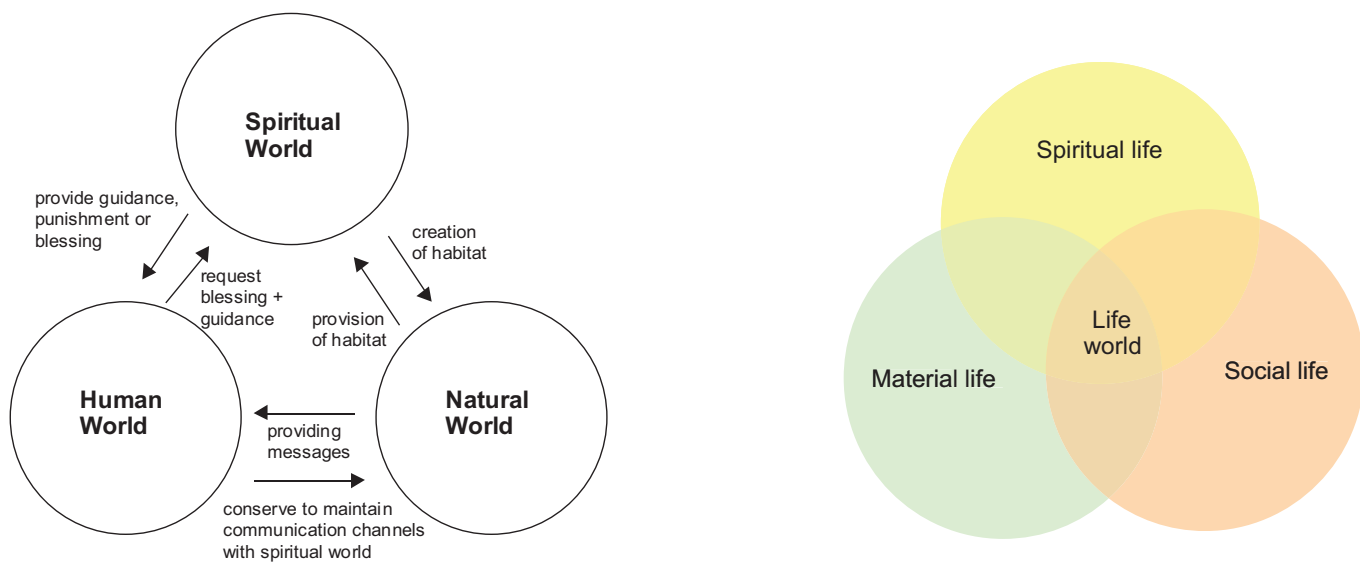

FIGURE 2.1 The three worlds in indigenous sciences and their interactions.

often different spiritual beings such as gods, spirits and ancestors. These spiritual beings may express themselves in nature and through living creatures.

- In many cosmovisions, nature is considered sacred. This finds its expression in concepts like Mother Earth, sacred mountains, rivers, trees and animals. Animals, plants and especially trees are often considered to be linked with the spiritual world and should be treated with respect. The sacred character of nature and the spirituality of the people often lead to the need to conduct rituals during agricultural activities. Some of these relate to spiritual beings or ancestors.

- Cosmic influences are frequently dealt with by using astrological information that determines the moments when different agricultural activities can take place. Thus, in many cases, the agricultural calendar and the ritual calendar are linked and they guide social, natural and spiritual activities.

- Indigenous communities organise themselves on the basis of their cosmovision. Many indigenous institutions regulate the use of land, water and biological resources as well as the way farmers learn, teach and experiment. Traditional leaders often combine their political powers with spiritual skills and functions.

- The way farmers learn and experiment is based on their own concepts, values and criteria.

- Many development activities and conventional systems of education and technology development neglect or reject the importance of cosmovision, culture and indigenous knowledge and suggest the superiority of dominant Western science. This Western scientific system tends to be less holistic and more materialistic than indigenous knowledge systems.

- There is no reason to romanticise cosmovisions. It cannot be concluded that indigenous cosmovisions and traditional practices have always been effective in preventing the overexploitation of soils, overgrazing, deforestation, pollution of water, erosion or environmental disaster. Nor have they always led to maintaining social stability or equity. Indigenous knowledge is not always equally spread in the communities, and some persons may monopolise and misuse certain knowledge.

- For development organisations to be effective, there is a need for them to support endogenous development. This is development that is based on locally available biological and physical resources and the values and knowledge of the local population. This implies a good understanding of the diversity of cultures and the characteristics and dynamics of indigenous knowledge systems and cosmovisions; cooperation with traditional leaders; an appreciation of the potentials and limitations of locally available resources 
for agriculture, health and nature management, and of their possible role in the local economy; and finally, a diversity of approaches to endogenous development that can be applied by local NGOs and governmental organisations for research and development. The partners of the COMPAS and CAPTURED programmes agreed that 'development' should be understood from the perspective of native cosmovision that implies the integration of spiritual life in social and material life. Yet there was a clear difference in the way that the different partners, acting as development agencies, could work with them. In the traditional communities in Bolivia and Ghana and the tribal areas in India, traditional cosmovisions are still quite intact.

- Agricultural production involves biophysical as well as spiritual activities. The agricultural calendar and the ritual calendar coincide. Here, the only way to have a good relationship with the rural population is to understand and appreciate their cosmovision and collaborate with indigenous institutions. In the rural areas in India, in Sri Lanka and in Peru, the traditional cosmovisions have been subjected to considerable erosion and it is difficult to get a good picture of rural people's cosmovision. There is a mixture of traditional and modern ideas that may differ from village to village and from year to year. In these areas, it was noticed that in initial discussions with farmers, traditional concepts were frequently not expressed. However, after further probing beyond the surface, many elements of the traditional cosmovisions gradually began to emerge. Farmers are used to the fact that outside agencies do not understand, respect or tolerate traditional practices or cosmovisions. Therefore, they talk with the outsider with empathy, in the language or concepts they think the outsider appreciates. They have learned that outsiders do not appreciate their cosmovision, and thus, they do not openly express their own concepts and views. There is reason to assume that in traditional societies, but also in countries where traditional cosmovisions are subject to erosion, traditional cosmovision and spirituality are more widespread and prevalent than assumed by outsiders in general. This means that working with traditional institutions is relevant and requires tact and social skills. In the Netherlands and Norway, and to a certain extent also in central Mexico, it seems that traditional cosmovisions and spirituality have almost completely disappeared. In these countries, there is a widespread discontent about the materialistic way of modern farming and a small number of farmers want to restore agriculture's spiritual vision. In such cases, indigenous institutions may no longer exist and, therefore, new institutional allies may have to be sought.

- In essence, the partners concluded that a focus on rural people's cosmovisions can make it possible to reconnect their work with indigenous knowledge in its full significance. Farmers interpret (agricultural) development and define their relationships with outside agencies from within the context of their cosmovision. Development workers are thus challenged to go beyond validating indigenous technical knowledge. Farmers' concepts of life - and the practices based on them - are a reality to which they must relate. This relationship can only be genuine when respect is given to the unknown concepts and traditional institutions. It also provides an opportunity for mutual learning.

The above lessons have been used to build a model for activities to enhance endogenous development (Figure 2.2).

\section{SPECIFIC AGRICULTURAL PRACTICES}

More in-depth studies in Sri Lanka, India, Ghana, Zimbabwe and Bolivia shine a light on specific agricultural practices where the spiritual dimension of the worldviews is being addressed.

Some practical examples are provided in Figures 2.3-2.9 below. 


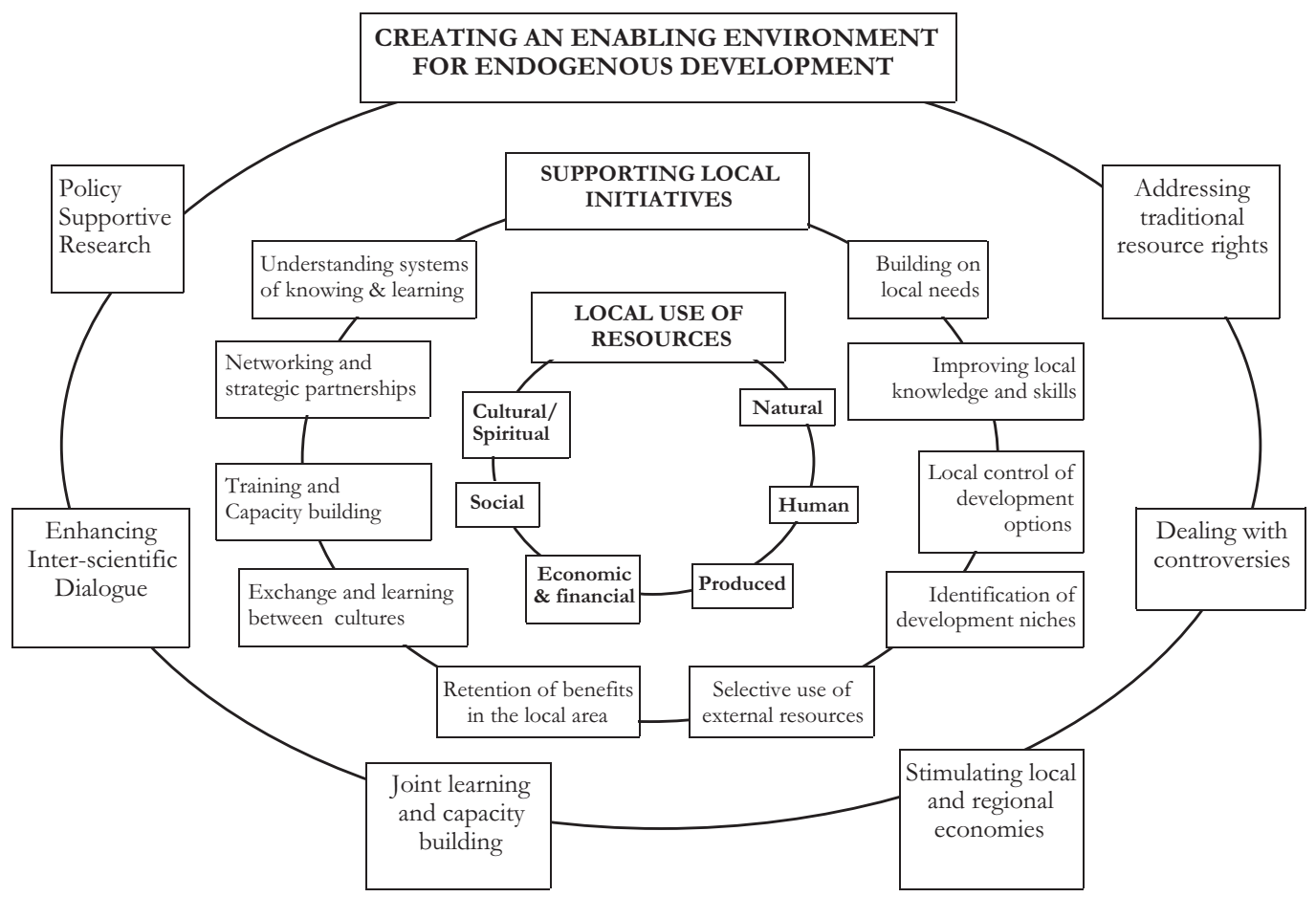

FIGURE 2.2 Creating an enabling environment for endogenous development. (Source: Haverkort et al., 2003: 250.)

\section{Sri Lanka: Mantras, Yantras and Kems}

A ritual in a rice field in Sri Lanka: a combination of mantras, meditation and sacrifices performed by a shaman. He has to live a pious life. The ritual is a commitment of people to the rice field and its natural environment, and a pledge for each being to play its role in the mutual process of coexistence and to avoid taking more than a fair share.
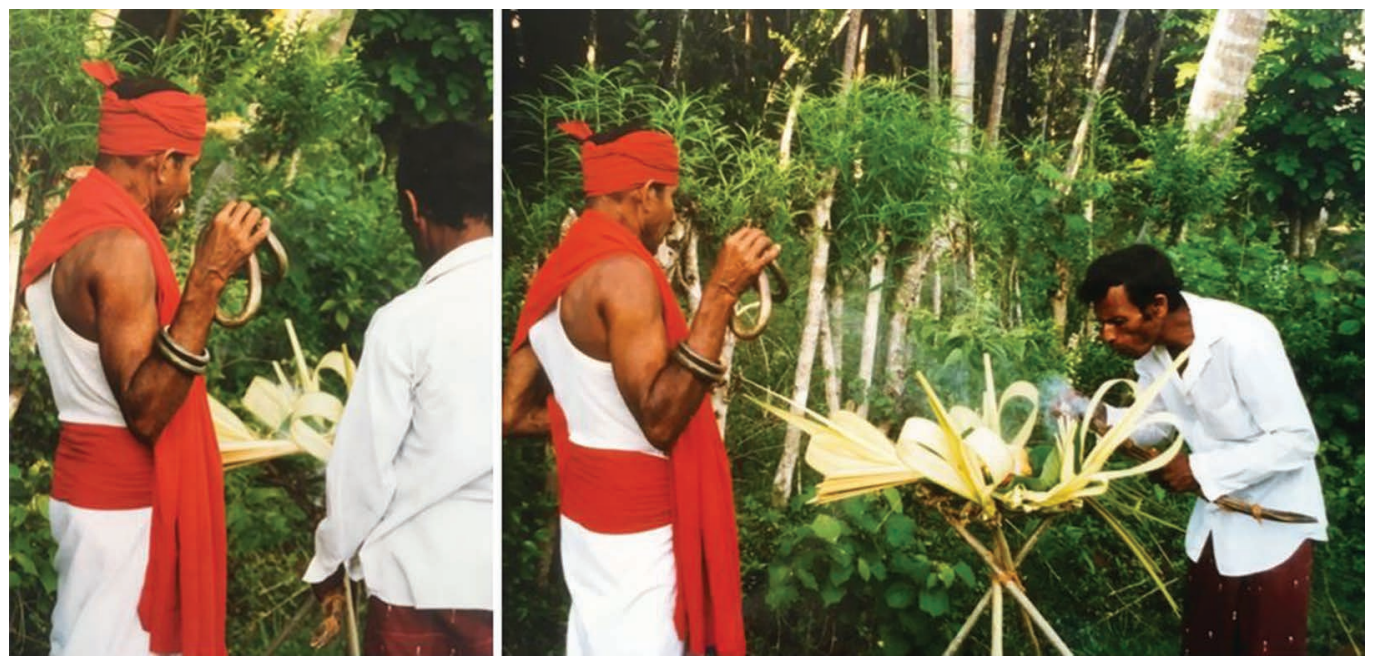

FIGURE 2.3 Ritual in a rice field in Sri Lanka. (Photo credit: author's own.) 


\section{AGNiHOtRA IN INDIA}

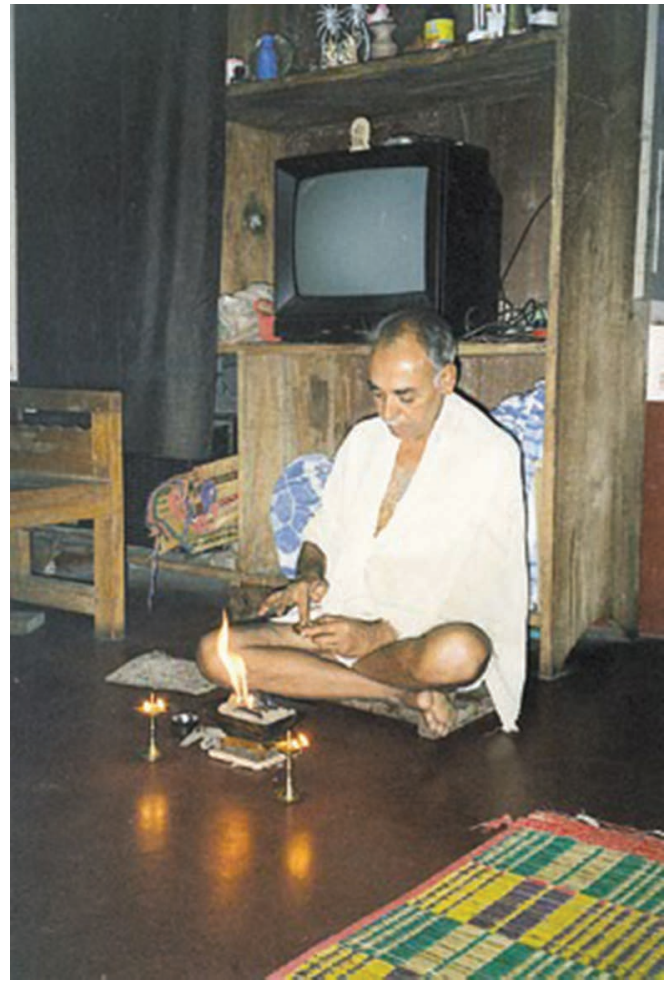

FIGURE 2.4 Agnihotra ceremony, India. (Photo credit: author's own.)

The leader of a farmer's group, Mr Perushotama Rao, performs a fire ritual, Agnihotra. Fire will purify the environment and allow for harmonious relations between plants, animals and human beings. Twice a day a mixture of ghee and rice will be put on the fire. Mr Rao chants a number of mantras, meditates and creates a vibration that causes a healthy environment.

\section{Sacrifices and Festivals in the Andes}

In the Andes, it is common to have rituals in the field to honour Pacha Mama and to establish and reinforce linkages between the land, the vegetation, the animals and people. There are specific rituals for strengthening the links with llamas, with potatoes or with other traditional crops. These are the moments when people celebrate community life amongst themselves.

\section{Seeking Ancestral Support in Africa}

In Zimbabwe, a spirit medium asks the blessing of the ancestors for a tree planting programme and mediates between the living and the dead to consult the ancestors and to build on their knowledge and wisdom.

In Northern Ghana, a soothsayer is consulted to ask the ancestors advice and permission for adopting a new technology. Animal and vegetative sacrifices are performed to mobilise magical powers.

\section{Harmonising the Earth and Cosmic Forces in Europe}

Biodynamic farmers in Europe use preparations in the form of cow horns filled with silica to mobilise cosmic forces. 

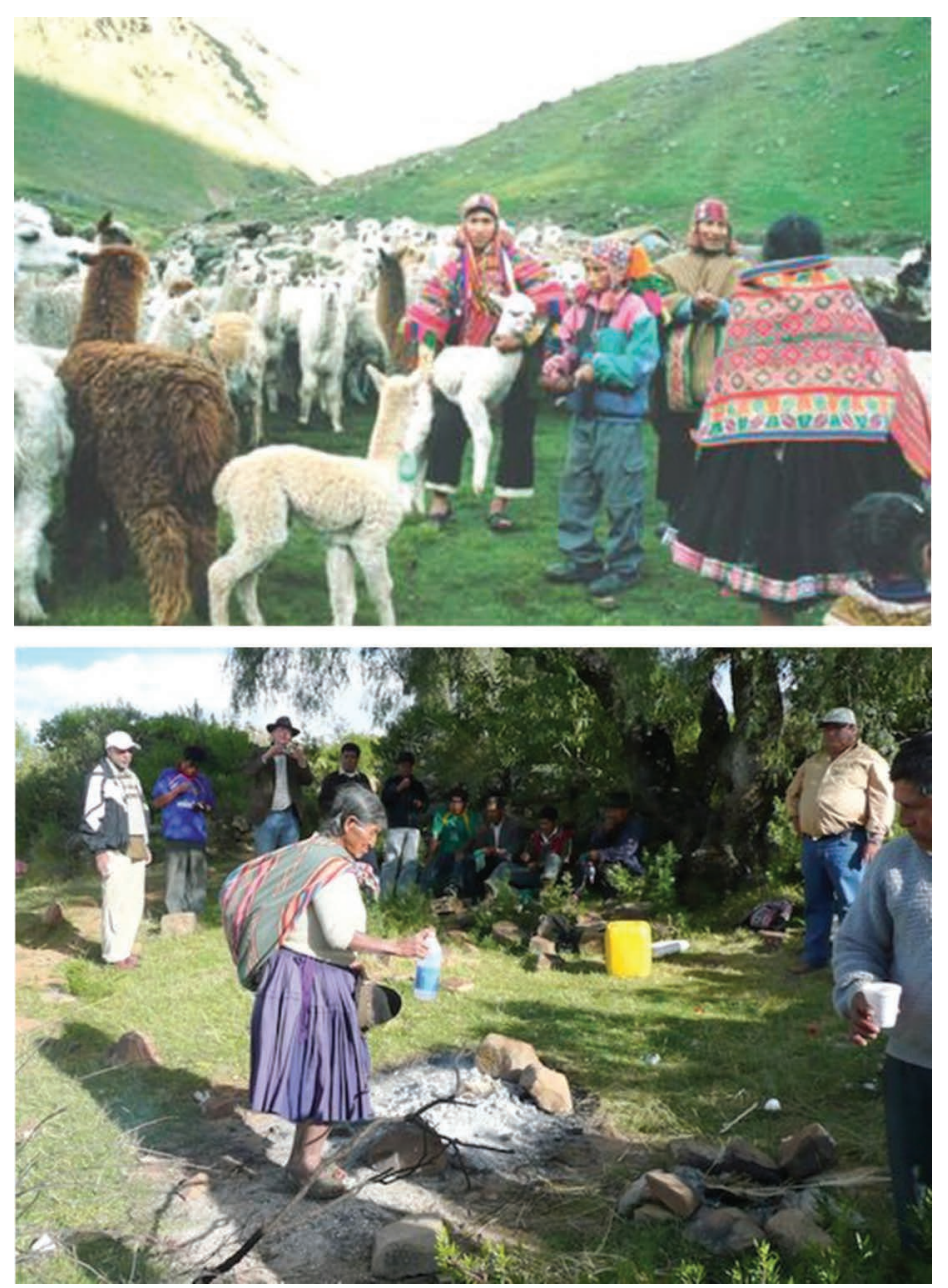

FIGURE 2.5 Pacha Mama ritual in the Andes. (Photo credit: author's own.)

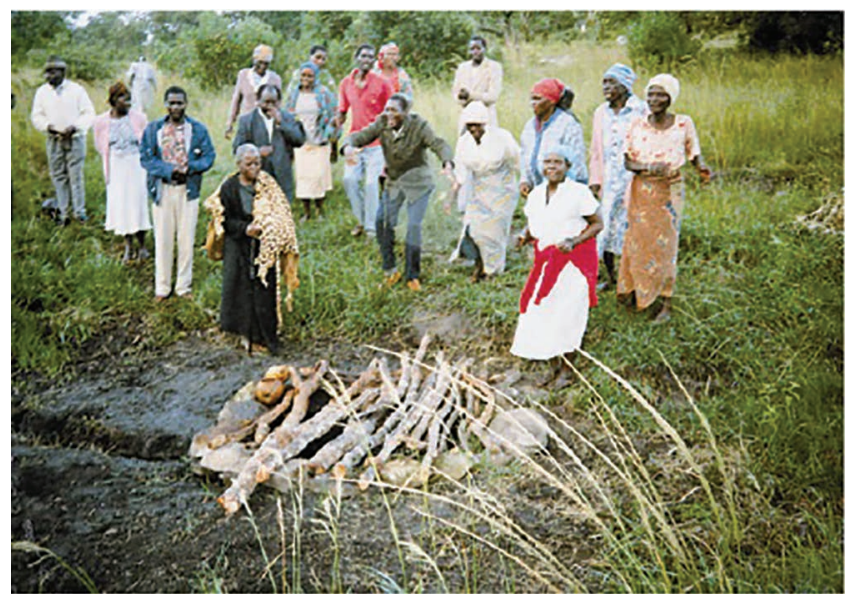

FIGURE 2.6 Ceremony to seek ancestral support in Zimbabwe. (Photo credit: author's own.) 


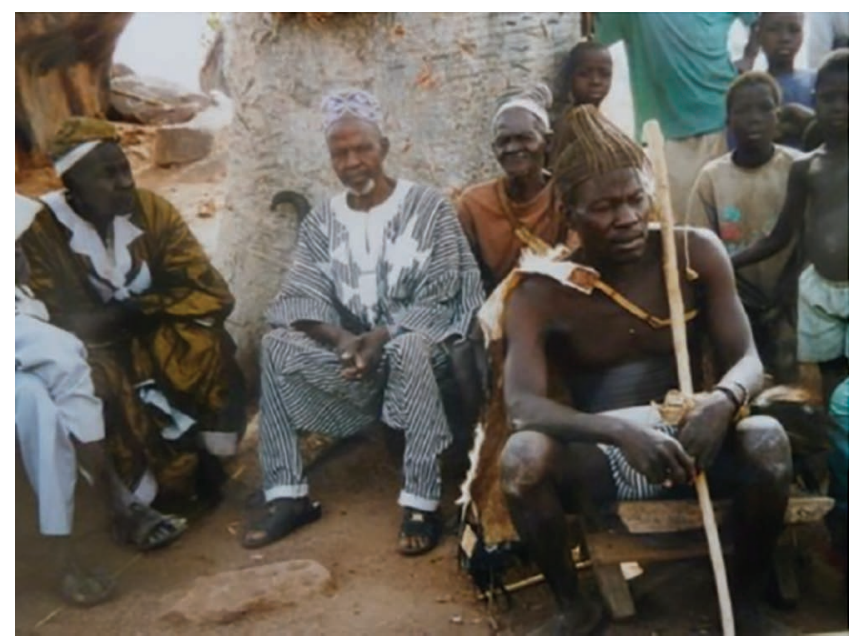

FIGURE 2.7 Consultation with the ancestors prior to adopting a new technology, Ghana. (Photo credit: author's own.)

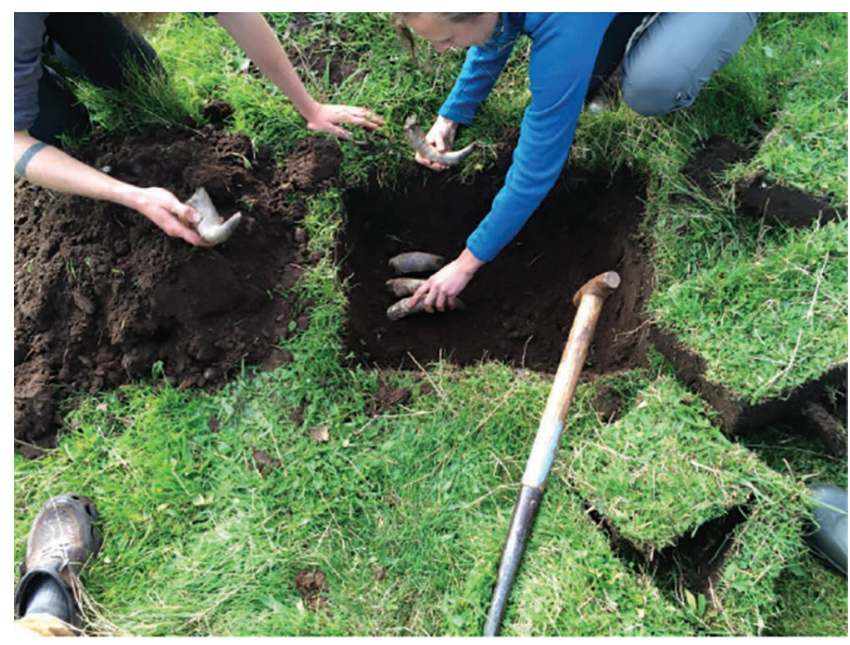

FIGURE 2.8 Group of farmers burying cow horns, Staffordshire, UK. (Photo credit: Alysoun Barrett Bolger.)

\section{THE TRANS-CULTURAL NOTION OF SCIENCE AND ITS CO-EVOLUTION}

Modern philosophers of science such as Popper, Kuhn, Latour and Feyerabend have each on their own, but especially in their combination, challenged the foundations of mainstream science and dismantled the idea of exclusive claims to universality. It goes beyond the scope of this chapter to delve deep into these (postmodern) notions of science. But in a very brief way, one can reflect on the following generalisations:

- Scientific knowledge is only an approximation to the truth. This approximation can be pursued by trial and error only (Popper, 1980, 1965).

- Scientific development should be as a social process in which the worldviews held by scientists and the social process of developing scientific activities should be understood. 
Real new knowledge emerges if the validity of the dominant paradigms is broadly being challenged and is replaced by new paradigms (Kuhn, 1962).

- Scientific facts are not in the first place objectively true; they are rather the result of agreement within the scientific community. This means that negotiation, networking and lobbying to get social recognition for the results of the research in the form of its publications are all important aspects of scientists' work (Latour and Woogar, 1979).

- Objective science is an illusion, as all observation, perception and interpretation are based on more or less deficient instruments and theories. What is considered to be a 'fact' is basically an agreement within a school of scientists. There is not one universally valid method of research, and the monopolistic claims to truth of conventional science are not justified. The history of sciences shows that there are different roads towards truth. Western science is one and only one of the possible sciences, and it is time to correct scientific arrogance and scientific imperialism. Exporting Western sciences and technologies has not exclusively brought well-being to indigenous peoples. We should stop the one-way traffic and rather go for a mutual learning process (Feyerabend, 1975).

Based on the reflections and positions of these philosophers of science, and building on the insights of indigenous scholars, CAPTURED has chosen the following definition of science: ${ }^{2}$

Science is a body of knowledge formulated within a specific worldview. It emerges from specific methods of learning and producing knowledge and uses a consistent theoretical framework that includes assumptions, general principles and theories. It involves an active role of a specific knowledge community that has reached consensus on validity of knowledge. The knowledge acquired and the resulting science are products of a social process and are always limited and subject to modification in the light of new data, information and insights.

The plurality of worldviews and ways of learning can lead to a plurality of sciences. The degree to which ontological positions and sources of knowing differ from each other determines the degree of compatibility and/or complementarity of different sciences. A joint learning process or dialogue between different forms of knowing would be impossible or meaningless if the sciences involved exclude each other. Even if the basic assumptions and methods may seem incommensurable, complementarity may be sought. The CAPTURED programme does not aim at integrating the different ways of knowing into one universal system of research and education. Rather, its focus is to understand the diversity, the differences, possible contradictions and controversies. It looks for revitalisation of the different ways of knowing and co-evolution and possible communalities, complementarities and synergy.

On the basis of this definition, the CAPTURED programme suggested that we look at a science as having a certain expression in each of the following basic elements:

- The Ontology (or Worldview): The way the people see themselves and their relation with the rest of the cosmos: the worldview

- The Gnoseology (or Methodology): Methods for learning, experimenting and teaching. It is obvious that the way of learning is a directly related to the worldview.

- The Epistemology (or the Theoretical Framework): The way knowledge is organised: its logic, theoretical frameworks and paradigms.

- The Axiology (or Values): The moral and aesthetic values of the people.

- The Knowledge Community: The experts, leaders, healers, guides and the way they carry out peer reviews, have debates and discourses on worldviews, methods, theories and values and agree on accepting or rejecting them.

In every culture, people have explicitly or implicitly formulated these notions and are engaged in these knowledge-related processes, and therefore, we assume that in different cultures and different

2 This definition and a discussion on the co-evolution of sciences have been elaborated in Haverkort et al. (2012). 
professional communities, different sciences exist. Some of these sciences are considered as rigorous in certain ways, and others may be considered as being weak in one or more aspects. The aim of the dialogue is to support each other in overcoming the weaknesses.

The plurality of worldviews, through methods of learning, in values, in conceptual frameworks and in ways to assess and review knowledge gained, can lead to a plurality of sciences. The degree in which ontological positions and sources and methods of knowing differ from each other determines the degree of compatibility and/or complementarity of different sciences. A joint learning process or dialogue between different forms of knowing would be very difficult if the basic elements of the sciences involved contradict each other.

The appreciation of the diversity of cultures and worldviews offers a wide range of opportunities for exchange and dialogue. Intercultural contacts can lead to domination and control, and thence to the disappearance of cultures and ways of knowing. But, if the intercultural contacts take place with respect, it can also lead to mutual learning and synergy. Respect does not imply the unconditional acceptance of all differences. It implies the willingness to listen, openness to learn and to be responsive, and the capacity to criticise when necessary (Fay, 1999).

COMPAS and CAPTURED provide a platform for intra- and intercultural and intra-/and inter-/scientific dialogues. Intra-cultural/scientific dialogues take place between persons that are from a particular culture and share a similar knowledge base, whereas intercultural/scientific dialogues take place between persons with a different cultural and scientific background. These exchanges can contribute to a co-evolution of cultures and sciences. In this process, no science is considered a priori superior of inferior. Traditional knowledge is not romanticised and Western knowledge not rejected because of its dominant position. Each science involved is stimulated to develop and improve its methods and theories based on its own dynamics as well as on interaction with other systems of knowing.

The Objectives of Inter-Scientific Dialogues Are as Follows:

- to strengthen and revitalise the marginalised sciences;

- to look for synergy and opportunities for mutual learning as well as for contradictions and exclusions;

- to question, challenge and criticise each other in order to determine those aspects of the science and value systems that need modification and improvement; and

- to balance the power and financial resource base of the different sciences.

The epistemological interpretation of the different Asian, African and Latin American and European knowledge systems, their ways of learning and experimenting and their mutual relationships needs further attention. Therefore, it is important to continue to systematise and make more explicit the concepts and theories behind indigenous forms of knowledge in order to share and improve on them as part of a possible co-evolution of the diversity of sciences.

\section{SCENARIOS FOR INTER-SCIENCE RELATIONS: FROM DOMINATION TO COMPLEMENTARITY}

Complementarity and co-evolution of sciences can only be obtained if the research methods and parameters used are not solely based on those of the dominant or on those of traditional science. The research needs to enhance the ownership, effectiveness and innovativeness of the different sciences involved and to include attention to worldviews, methods, theories, values and knowledge communities. All the research being carried out in the CAPTURED programme focused on these aspects, with the main research tools being transdisciplinary research (Nicolescou, 2004, 1998), action research and indigenous methodologies (Denzin et al., 2008). In all cases, methods and parameters of different scientific traditions are combined, and the knowledge communities of both mainstream and local sciences are involved in the design, implementation and follow-up of the research. 


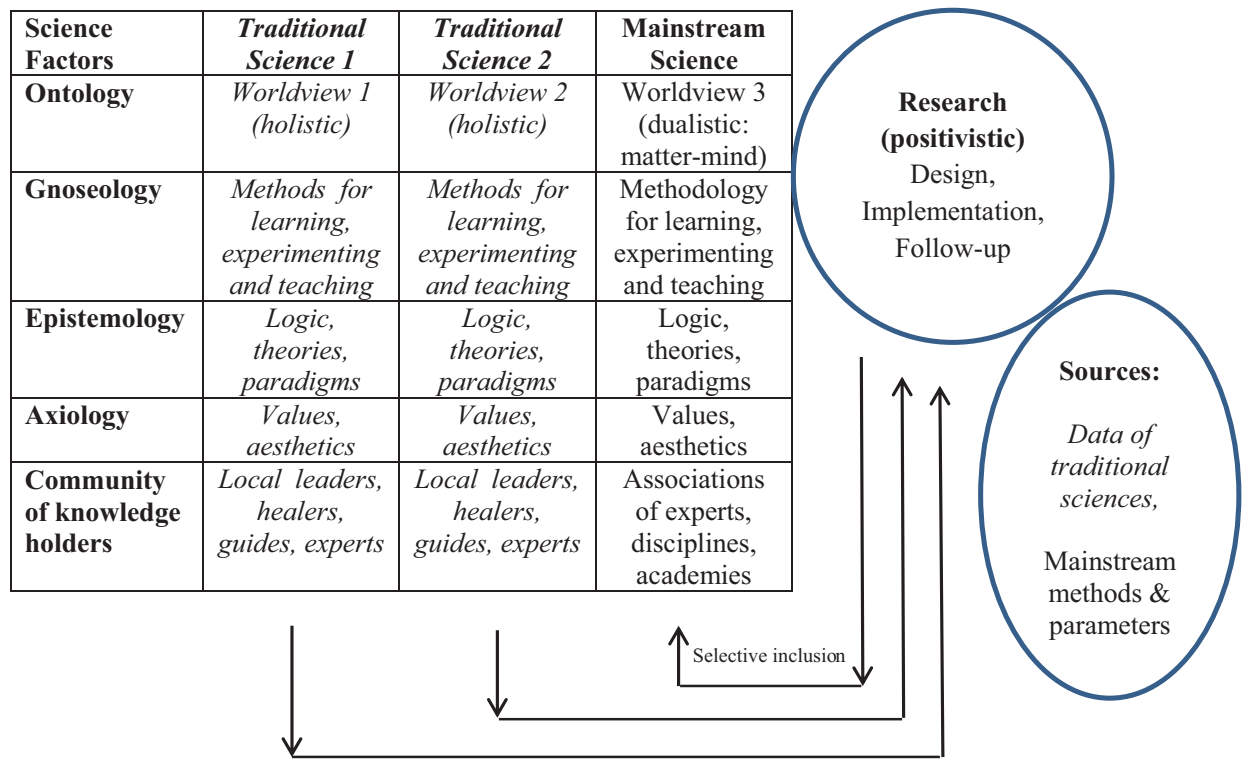

FIGURE 2.9 Scenario 1: marginalisation: suppression, substitution and selective inclusion.

Below, two different scenarios for relating sciences are presented:

Scenario 1: This leads to marginalisation and suppression of local sciences, to substitution by mainstream knowledge and selective inclusion of traditional knowledge in the mainstream, shown in Figure 2.9. This may lead to underground or parallel knowledge systems, to syncretism and/or rebellion or resistance.

Scenario 2: This leads to complementarity, synergy and co-evolution of different sciences, as shown in Figure 2.10.

Assessment of traditional sciences by the mainstream in a one-way process (as shown by the arrows in Figure 2.9). Mainstream research uses positivistic models with mainstream parameters to assess traditional technologies. It may include those elements of local knowledge in its system which are considered positive according to the researchers' parameters, with no feedback to traditional sciences. This often leads to marginalisation, suppression and substitution, 'going underground', syncretism and resistance.

Flows of data and research results to and from all sciences are shown by the arrows in Figure 2.10.

The involvement of actors in the design, implementation and follow-up is defined by protocols and codes of conduct. Inter-science dialogue leads to complementarity, synergy and co-evolution. Research methods can be both quantitative and qualitative and should also involve information exchange and dialogues between social actors such as artists, religious leaders, syndicates, political, emancipatory and environmental movements, business and minorities.

\section{POSSIBLE CHALLENGES AND OPPORTUNITIES}

CAPTURED concluded that there are a number of approaches that together could contribute furthering inter-scientific dialogue that involves local communities, NGOs, universities and regional and international organisations.

\section{Redefining the Role Of Universities}

A prime condition for successful cooperation of these actors will be a relationship between actors that is horizontal as far as possible and is characterised by mutual interest and confidence. Hence, 


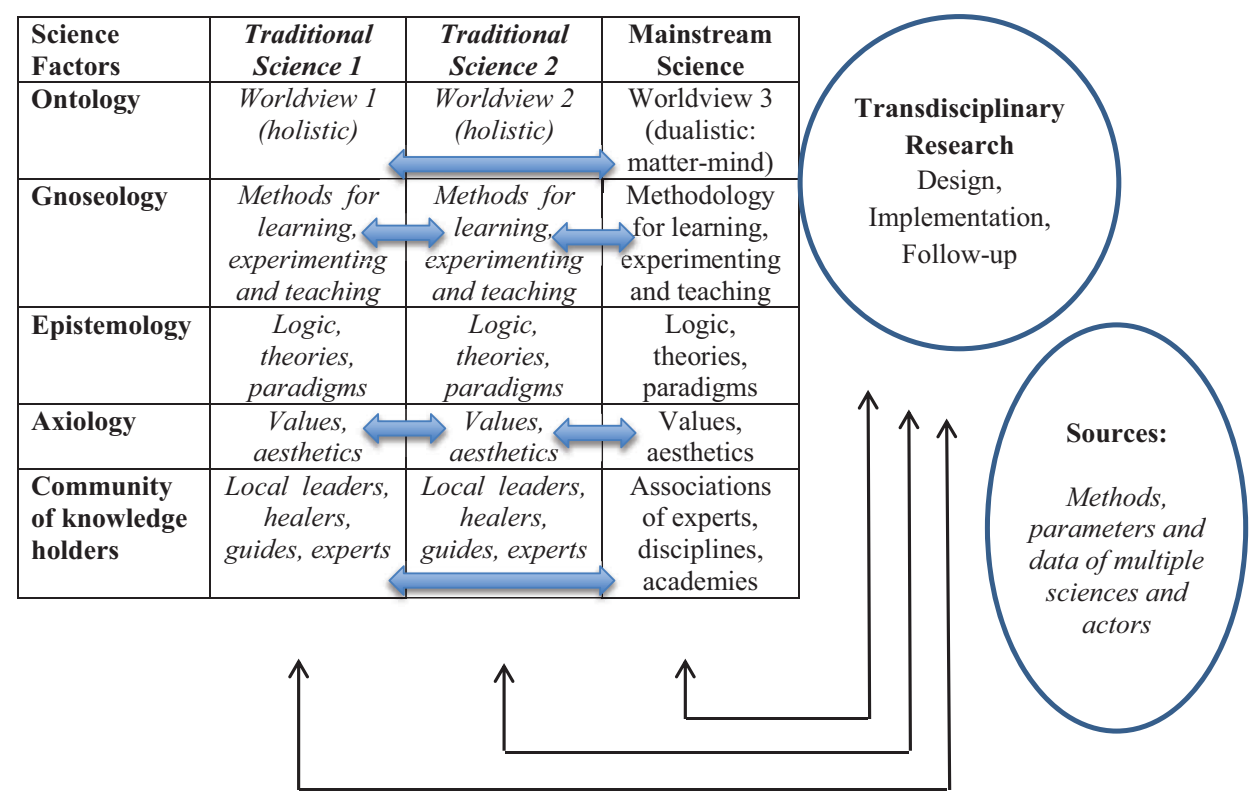

FIGURE 2.10 Scenario 2: complementarity and co-evolution of different sciences.

the first step to take is to critically analyse and reconstruct the different relationships as they currently exist. Field staff and researchers working with rural people have to make clear that their role is not that of an external agent who comes with a certain message or technology to be transferred. Learning with and from local people, and working on the basis of their cosmovision, implies that the outsiders accept the rules of the game as expressed by the communities. The traditional codes for hospitality, confidence building, respect and communication have to be accepted and obeyed. This may mean procedures of selection and processes of initiation, and participation in rituals that have a different cultural background and meaning for local people than for outsiders.

Universities have to accept the fact that their conventional knowledge has its limitations, and also have to accept that their role in this process is predominantly one of learning. Their funding agencies have to get used to downward accountability. The communication and interaction will not only be about conventional professional subjects, but will also involve spiritual and cultural aspects, and a lot will depend on good social relations and skills. This means that the role of supporting people and organisations changes radically: instead of teaching local people how to resolve their manifold problems, they concentrate on learning from local people as the basis for exploring possible synergies between different forms of knowledge. External actors become companions and animators of communications within and between different groups related to endogenous development. This requires a process of personal preparation, where the conventional professional standards, attitudes and skills are scrutinised and modified where necessary.

It is important to find out to what extent local communities are already engaged with the dominant system. Is it possible to describe the relationship of the local culture and way of knowing with the formal/dominant system in the area? Can we learn from the community how they have managed to survive/change and co-evolve with the dominant/formal system? How do they do it? And, how shall NGOs, universities or other supporting organisations relate to that, and deal with this when certain value differences between 'us' and 'them' become clear? What are the possibilities and limitations for intercultural dialogue? 


\section{Dealing with the Strong and Weak Points within the Dominant Forms of Knowledge}

The basic hypothesis of this chapter is that Western knowledge is just one of the possible forms of knowledge. It is not universally applicable. It has its own strengths and weaknesses. An intercultural dialogue based on mutual confidence and horizontal relationships can only take place if all partners involved are prepared to have a self-critical attitude. There are considerable theories and reflections on the character of Western science. In the battlefield of knowledge, debates are held on issues such as objectivity versus subjectivity; universalism versus relativism; specialisation and disciplinarity versus holism or transdisciplinarity; quantitative methods and qualitative methods; and neo-positivism and actor perspectives. Hence, it is clear that also within the dominant 'scientific tower', there are different perspectives and positions. Western knowledge applied to agriculture or health practices has great impact across the globe. It has led to impressive results, but it has not been able to solve all problems related to food security, health, poverty, environmental sustainability and peace. Therefore, there is a perspective for intercultural and inter-scientific dialogue, on condition that Western science also accepts its limitations and is interested in finding ways to deal with them. The balance between sources of knowing-rationality, quantification and the material world, on the one hand, and empathy, intuition, sense and meaning, on the other - needs to be explored and, where necessary, corrected. Non-Western scientific traditions can offer a lot to Western science, and the other way around.

\section{Challenging the Dominant Worldview and Epistemology}

The dominant/mainstream/Western worldview is biased in its dualistic and materialist orientation, and this bias contributes to the existing global ecological, social and spiritual problems. Human behaviour leading to these crises has its roots in the dominant values and the way knowledge and technologies are produced. There is a clear link between the dominant scientific knowledge and the way economic development is governed by the laws of capital (Molenaar, 2006).

As the dominant worldview is at least partly responsible for the poly-crisis in the world, it is being challenged from several angles. More and more the conventional, materialistic and science-based approaches to development are being questioned, and innovative individuals, citizen groups, scientists and policy makers are presenting new ideas on how things can be done.

\section{CONCLUSION: DIALOGUES BETWEEN AND ABOUT SCIENCES}

The insight is emerging that we should look at worldviews, sciences and values, not as universal, where in the end one of the options will turn out to be the best, but as expressions of a pluralist reality. In this view, intercultural dialogues, mutual learning and co-evolution of the diversity of sciences are important. But then, how can we form rules for understanding and exchange between individual knowledge systems? To what extent can we expect contradiction, synergy or complementarity between different forms of knowledge? How can we make an exchange between, for example, Maya knowledge, Shona knowledge, Hindu and Buddhist knowledge, European and global knowledge beneficial for the participants?

Two conditions have been suggested (Klein, 2005) for a fruitful dialogue:

- Acceptance of pluralism, and

- Symmetry in power and resources.

The different partners in the dialogue need to accept that, even though they believe that (considering possible limitations) their own view is probably the best option for their own context, other views may be relevant for other contexts. In other words, there may be more than one way to interpret, study and understand reality.

Symmetry in power, in prestige and in access to human and financial resources will avoid a situation where a dominant system determines the rules of the game. Local knowledge may be weaker 
than mainstream knowledge as the result of historic processes that have led to the discrimination of local knowledge or asymmetric funding of research. But local knowledge should not be assessed by applying the criteria and methods used by mainstream science.

In the current international scientific arena, the rhetoric around the acceptance of pluralism and symmetry is far from the reality. The West has a dominant position in the globe: economically, militarily, ideologically and scientifically; and this makes acceptance of pluralism and symmetric relationships with non-Western systems very difficult.

For inter-scientific cooperation, it is important to have a formulation of the characteristics of different ways of knowing (in terms of the ontology, gnoseology and epistemology) and a self-assessment of the relative strengths and weaknesses of each knowledge system. This could coincide with an assessment of the power relations between the systems involved. During a conference on intra- and inter-scientific dialogue, AGRUCO and Latin American COMPAS partners concluded that intra-cultural dialogue and a revitalisation of indigenous knowledge are preconditions for inter-scientific dialogues (Delgado and Escobar, 2006).

This means that for each scientific tradition that takes part in inter-scientific cooperation, its own worldview should be formulated by the holders of that view themselves. The way of learning should be made explicit and should be the basis on which an epistemology can be formulated. This is not a simple process; it involves different actors, may require time and resources and may lead to confusion or frustration or reveal internal differences.

The objectives of the intra- and inter-scientific dialogues are as follows:

- To understand, describe and exchange the epistemologies and paradigms of the sciences involved.

- To strengthen and revitalise marginalised sciences by providing them sufficient space to flourish in knowledge institutions.

- To determine the strengths, limitations and comparative advantage of each science.

- To look for synergy and opportunities for mutual learning as well as for contradictions and exclusions.

- To question, challenge and criticise each science in order to determine those aspects of the science and value systems that need modification and improvement.

- To promote policies that facilitate balancing the power and financial resource base of the different sciences.

Today, the mainstream 'knowledge space' in institutions for education, research and development is largely dominated by Western science, its values and its epistemic frame. This impoverishes not only the knowledge sector but also development programmes that are based on one dominant knowledge system. The epistemological interpretation of the different Asian, African and Latin American and European knowledge systems, their ways of learning and experimenting and their mutual relationships needs urgent attention, if we are to diversify and enrich both the world's knowledge space and development action. Therefore, it is important to systematise and make more explicit the concepts and theories behind indigenous forms of knowledge in order to share them as part of a possible co-evolution of the diversity of sciences.

\section{REFERENCES}

AGRUCO (2001) Cosmovision Indigena y Biodiversidad en America Latina - Seminario Latinoamericano en Cochabamba. Bolivia: Biodiversidad - Sustento y Culturas, 28 Abril de 2001.

Balasubramanian, A.V. and Nirmala Devi, T.D. (eds.) (2006) Traditional knowledge systems of India and Sri Lanka. Papers Presented at the COMPAS Asian Regional Workshop on Traditional Knowledge Systems and Their Current Relevance and Applications, 3-5 July 2006, Bangalore. COMPAS series on Worldviews and Sciences 5. COMPAS/CIKS September 2006. 
Barnhardt, R. and Kawagley, A.O. (2005) Indigenous knowledge systems and Alaska Native ways of knowing. Anthropology and Education Quarterly, 36(1): 8-23.

Battiste, M. (2005) State of Aboriginal Learning. Ottawa, ON: Canadian Council on Learning, 75 pp.

Bishop, R. (1998) Freeing ourselves from neo-colonial domination in research: A Maori approach in creating knowledge. International Journal of Qualitative Studies in Education, 11: 199-219.

Cajete, G. (2000) Native Science: Natural Laws of Interdependence. Santa Fe, NM: Clear Light Publishers.

COMPAS (2007) Learning Endogenous Development, Building on Bio-Cultural Development. London: Practical Action Publishers/ETC Foundation.

COMPAS-AGRUCO (1998) Plataforma para el Dialogo Intercultural Sobre Cosmovision y Agricultura. Cochabamba: Plural-CID.

Delgado, F. and Escobar, C. (eds.) (2006) Dialogo Intercultura e Intercientifico, Para el Fortalecimiento de las Ciencias de los Pueblos Indigenas Originario. COMPAS and AGRUCO. La Paz: Edicion Plural.

Denzin, N.K., Lincoln, Y.S., and Smith, L.T. (2008) Handbook of Critical and Indigenous Methodologies. London: Sage Publications.

Fay, B. (1999) Contemporary Philosophy of Social Sciences; a Multicultural Approach. Malden, MA: Blackwell Publishers.

Feyerabend, P.K., (1975) Against Method; Outline for an Anarchistic Theory of Knowledge. London: New Left Books, 375 p.

Haverkort, B. and Reijntjes, C. (eds.) (2006) Moving Worldview: Reshaping Sciences, Policies and Practices for Endogenous Sustainable Development. Leusden: COMPAS, Maastricht: ECDPM, and Bern: CDE.

Haverkort, B., van t Hooft, K., and Hiemstra, W. (2003) Ancient Roots, New Shoots: Endogenous Development in Practice. Leusden: COMPAS and London: Zed Books.

Haverkort, B., Delgado Burgoa, F., Shankar, D., and Millar, D. (eds.) (2012) Towards Cocreation of Sciences: Building on the Plurality of Worldviews, Values and Methods in Different Knowledge Communities. Bangalore: Nimby Books, $291 \mathrm{p}$.

Klein, G.K. (2005) Three centuries of global population growth: A spatial referenced population (density) database for 1700-2000. Population and Environment, 26(4): 243-367.

Kuhn, T. (1962) The Structure of Scientific Revolutions. Chicago, IL: University of Chicago Press.

Latour, B. and Woogar, S. (1979) Laboratory Life: The Construction of Scientific Facts. Beverly Hills, CA: Sage Publications.

Mihesuah, D.A. and Wilson, A.C. (2004) Indigenizing the Academy; Transforming Scholarship and Empowering Communities. Contemporary Indigenous Issues Series. Lincoln: University of Nebraska Press, $246 \mathrm{p}$.

Millar, D., Kendie, S.B., Atia Apusigah, A., and Haverkort, B. (eds.) (2006) African Knowledges and Sciences: Understanding and supporting the ways of knowing in Sub-Saharan Africa. COMPAS Series on Worldviews and Sciences 3. Leusden, The Netherlands, Navrongo and Cape Coast, Ghana: Comparing and Supporting Endogenous Development (COMPAS), University of Development Studies (UDS), University of Cape Coast (UCC).

Molenaar, P.C. (2006) Psychophysical dualism from the point of view of a working psychologist. Erkenntnis, 65(1): 47-69.

Nicolescou, B. (1998) The transdisciplinary evolution of the university, condition for sustainable development. International Congress 'Universities Responsibilities to Society', International Association of Universities, Chulalongkorn University, Bangkok, Thailand, November 12-14 1997. Paris: CIRET, Rencontres.

Nicolescou, B. (2004) Toward a methodology foundation of the dialogue between technoscientific and spiritual cultures. In Morena, L.M. (ed.), Differentiation and Integration of Worldviews: Philosophical and Religious Experience. Saint Petersburg: Eidos.

Popper, K. (1965) Conjectures and Refutation: The Growth of Scientific Knowledge. London: Routledge.

Popper, K. (1980) The Logic of Scientific Discovery. London: Hutchinson and Co.

Rist, S. and Delgado, F. (2009) Strengthening endogenous knowledge production through intercultural dialogue. In: Hoffmann, V., Christinck, A., and Lemma, M. (eds.), Handbook: Rural Extension: Examples and Background Material. Weikersheim: Margraf Publishers, vol. 2: 346-353.

Tuhiwai Smith, L. (1999) Decolonizing Methodologies: Research and Indigenous Peoples. London/New York: Zed Books.

van der Ploeg, J.D. (2008) The New Peasantries; Struggles for Autonomy and Sustainability in an Era of Empire and Globalisation. London and Sterling, VA: Earthscan. 